\title{
Cubans' Deadly Diet: A Wakeup Call
}

\section{By Carmen Porrata, MD, PhD}

Learning to live and eat differently is essential to turning back the global epidemic of chronic diseases. And Cubans are no exception.

As a rule, Cubans scarcely consume whole-grain cereals, fruits, or leafy green and other vegetables. But we have a relatively high consumption of saturated fats, sugars, refined cereals, animalorigin foods, sweets of all kinds, salt, and "junk foods" loaded with chemical additives. Mealtimes tend to be irregular, we eat on-therun, and foods are often poorly handled and elaborated.

Thus, we see an alarming increase in the number of people who are overweight or obese, with a rise in chronic disease just around the corner. More troubling still are bad eating habits in children, provoking damage that can have health consequences for life.

My mentor in balanced nutrition, Professor Mario Pianesi, believes that eating is the most important thing you can do for life. He's right: the quality of our blood, cellular life, and metabolism all depend on the quality of what we eat and drink. So 'we are what we eat' is not far from the truth. But how many of us think about that when we sit down for a meal?

\section{The ham and cheese sandwich is Cubans' number one favorite food}

In Cuba, everyday eating tends to be mechanical: we eat or drink what's handy when we're hungry.

What we like best is what we eat most often, depending of course on our pocketbooks. Now we begin to see the results, according to the 2nd National Survey on Risk Factors and Chronic Diseases (2001):

- Minimal consumption of fish, due to taste preference.

- Virtually zero consumption of whole-grain cereals; these foods were not preferred, and people were unfamiliar with them.

- Only $17 \%$ consumed adequate vegetables daily (three portions recommended); and $16 \%$ adequate fruits (two portions recommended). This pattern due to a taste preference.

- Excessive sugar consumption, a function of taste. One-half consumed over $20 \%$ of their calories in sugar.

- Use of bouillon cubes and industrial seasonings for all meals.

- Excessive use of salt in cooking and added at mealtime.

- Low consumption of dietetic fiber ( $14 \mathrm{~g}$ per day).

- General use of powdered drink mixes for children's snacks.

- General use of reheated oils.

- Greater consumption of red over white meats. And if they could, $70 \%$ of the Cuban population would eat meat in excess.

- $\quad 90 \%$ would choose to eat fried foods at nearly all meals.

- $\quad 89 \%$ would consume animal and vegetable fats in excess (oil, lard, butter, mayonnaise, bacon, pork cracklings).

- $\quad 90 \%$ would eat ham at least once a day. The ham and cheese sandwich was listed as the number one favorite food.
- Over $90 \%$ said they would prefer commercially produced soft drinks (carbonated or powdered mixes) with meals.

- $79 \%$ would consume dairy products in excess (more than two portions daily).

- $60 \%$ would consume eggs every day, directly or in dishes like desserts or salads.

- $\quad 82 \%$ ate at least one meal on-the-go every day, purchased from sidewalk vendors or fast food outlets.

The average Cuban's first choice was to spend their money on animal-origin foods and fats, then on more rice and root vegetables, and lastly on fruits and vegetables.

Little research has been done in Cuba on the public's knowledge of diet and health. Surveys of adults for five master's degree theses at the Institute of Nutrition and Food Hygiene (2002) offer some clues:

- $50 \%$ of those surveyed did not relate diet to health.

- Food selections were made primarily by taste and budget.

- Vegetable oil was named as the healthiest of all fats, but those surveyed were unaware of the risk of reheating it.

- $\quad 25 \%$ were unaware of cholesterol's damaging effects.

- $\quad$ Fruits and vegetables were identified as a source of vitamins $(90 \%)$, but only $20 \%$ identified them as a source of fiber. Over $60 \%$ said meat was a source of fiber.

- Only $30 \%$ referred to beans as a source of protein.

- $\quad 98 \%$ said that meat should be eaten every day, and $90 \%$ considered red meat (primarily beef) the healthiest.

- $\quad 85 \%$ thought ham was a very good food, especially for children, and would feed their children ham every day if they could.

- Only $28 \%$ knew that fish was a healthy choice.

- $30 \%$ were unaware of excess sugar's damaging effects.

- $85 \%$ were not familiar with health risks associated with commercially produced soft drinks; bouillon cubes; other industrial seasonings; or salty, cured, smoked, and fried foods.

These surveys show public knowledge of diet and nutrition is low, despite the educational level of the adults surveyed $-97 \%$ had at least junior high school level, and over $50 \%$ were high school or university graduates.

Our public health policies and programs should give priority to diet and nutrition, developing strategies that cut across all sectors. We must boost availability and accessibility of healthy foods and launch a national nutrition education program that empowers people to make wise decisions on selection, combination, and preparation of their food. Health personnel should also be better educated about diet and nutrition - something I believe is particularly urgent.

We must act now to prevent the loss of thousands of lives and avoid the social and economic consequences for our country from the approaching epidemic of chronic diseases. By learning to eat simply and eat the most natural foods possible, we take more responsibility for our health and our lives. -1 - 